\title{
Do We Need Extensor Retinacular Enhancement on Broström Lateral Ankle Repair? A Systematic Review and Meta-analysis
}

\author{
John Butarbutar ${ }^{1 *}$ (D) Irvan Irvan ${ }^{1}$, Michael Anthonius $\operatorname{Lim}^{1}$ (i), Raymond Pranata ${ }^{2}$ (D) \\ ${ }^{1}$ Department of Orthopedics and Traumatology, Faculty of Medicine, Universitas Pelita Harapan, Siloam Hospitals Lippo \\ Village, Tangerang, Indonesia; ${ }^{2}$ Department of Orthopedics and Traumatology, Faculty of Medicine, Universitas Pelita Harapan, \\ Tangerang, Indonesia
}

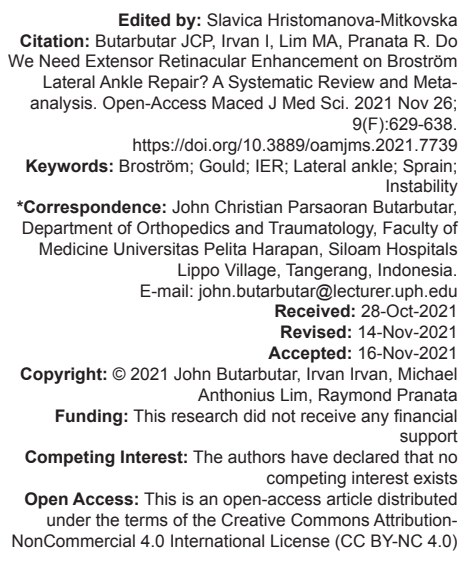

\begin{abstract}
BACKGROUND: This meta-analysis compared inferior extensor retinaculum (IER) enhancement in Broström-Gould procedure and anatomical Broström repair.

AIM: We aim to evaluate functional ankle score (American Orthopaedic Foot and Ankle Society [AOFAS] score and Karlsson score), talar tilt, talar anterior translation, and complications between both groups.

METHODS: A comprehensive systematic literature search was carried out using Wiley Library, Scopus, PubMed, ScienceDirect, and Europe PMC databases from inception up until December 19, 2020. While the intervention was IER enhancement, the control was those without IER enhancement. The primary outcome was the functional ankle score (AOFAS and Karlsson score). The secondary outcomes were talar tilt, talar anterior translation, and other complications.

RESULTS: There were a total of 298 patients from seven studies included in this systematic review and meta-analysis. IER enhancement was associated with lower AOFAS (mean difference -1.115 [ $-2.197,-0.033], p=0.043 ; 1^{2:} 0 \%$ ) during follow-up. Lower Karlsson score was observed in the IER enhancement group (mean difference -2.004 [-3.442, -0.567$]$, $p=0.006 ; l^{2} 3.71 \%$ ) during follow-up. Talar tilt (mean difference $-0.145^{\circ}[-0.436,0.146], p=0.329 ; I^{2}: 0 \%$ ) and anterio displacement (mean difference $-0.109 \mathrm{~mm}[-0.096,0.314], p=0.299 ; I^{2} 0 \%$ ) in the two groups were similar on follow-up. The complications were similar in both groups (OR $0.87[0.40,1.89], p=0.719 ; 1^{2:} 0 \%$ ). Meta-regression analysis indicates that the association between IER and AOFAS was not affected by age $(p=0.927)$ and male gender $(p=0.930)$

CONCLUSION: This meta-analysis showed that anterior talofibular ligament repair with non-IER enhancement was non-inferior compared to those with IER enhancement.
\end{abstract}

\section{Introduction}

An ankle sprain is one of the most common sports-related injuries with $20 \%$ recurrences, and up to $70 \%$ of patients still have residual symptoms after conservative treatments [1], [2]. Anterior talofibular ligament (ATFL) is the most frequently injured followed by the calcaneofibular ligament (CFL) [3], [4], [5]. Broström introduced the ATFL repair technique in 1966 [6]. This technique involved approximation and direct sutures of the torn ATFL. Broström also used osseous suture to lateral malleolus on latter publication in the same year. In 1980, Gould presented the idea that the Broström procedure could be enhanced by suturing the talocalcaneal ligament and inferior extensor retinaculum (IER) to the lateral malleolus. Since then, the Broström-Gould procedure [7] has become the gold standard for surgical management of lateral ankle instability [8], [9], [10], [11]. Later, several modifications of the Broström-Gould procedure have been reported, including the use of anchor sutures and the arthroscopic technique [12], [13].
Several biomechanical studies compared Broström and Broström Gould repair; however, the results were inconclusive. Aydogan et al. [14] observed that IER enhancement provided biomechanical benefits. Meanwhile, two studies showed similar biomechanical results between non-IER enhancement and IER enhancement [15], [16], [17]. Furthermore, Bell et al. [18] conducted a long-term observational study on the Broström repair procedure and showed a satisfactory outcome. Hence, the biomechanical advantages of IER enhancement may not translate into clinical benefits.

Amid the increasing popularity of arthroscopic repair for ankle instability, the question of whether IER enhancement is needed arises [10]. An increasing number of studies showed similar results in terms of clinical outcomes between arthroscopic and open Broström repair. Arthroscopy offers the additional benefit of addressing intra-articular problems at the same time. However, percutaneous IER enhancement during an arthroscopic procedure is technically intricate [19], [20].

The question addressed by this systematic review is whether the Broström-Gould procedure 
is clinically superior to Broström repair. We aim to compare functional ankle score (American Orthopaedic Foot and Ankle Society [AOFAS] and Karlsson score), talar tilt, talar anterior translation, and complications between both groups.

\section{Methods}

This study follows the recommendation by the Preferred Reporting Items for Systematic Reviews and Meta-Analyses. PROSPERO Registration Number: CRD42021227223.

\section{Inclusion and exclusion criteria}

Included studies should meet all of the following criteria: (1) Randomized controlled trial (RCT), prospective or retrospective observational study and (2) comparing IER enhancement and nonIER enhancement technique for chronic lateral ankle instability (CLAI) related to the outcome of interest (there is no language restriction).

The studies were excluded based on the following criteria: (1) Review articles, case reports, commentaries, editorials, letters, animal experiments, cadaveric studies, or technique articles; (2) noncomparative studies; (3) insufficient data, such as conference papers and abstract-only publication; and (4) duplicated studies.

\section{Outcome measures}

The intervention was IER enhancement, while the control was those without IER enhancement. The functional ankle score (AOFAS and Karlsson score) was the primary outcome, with mean differences as the effect estimate. The secondary outcome was talar tilt, talar anterior translation, and other complications. The effect estimate for these scores was mean differences for talar tilt and anterior translation; and odds ratio (OR) for the complications.

\section{Search strategy and study selection}

A comprehensive systematic literature search was carried out using Wiley Library, Scopus, PubMed, ScienceDirect, and Europe PMC databases from inception up until December 19, 2020, combining the following keywords: (Broström OR Gould OR "extensor retinaculum") AND ("lateral ankle" OR "ankle instability"). After removing duplicate records, three authors performed independent screening of the title/abstracts of the residual articles based on the inclusion and exclusion criteria.

\section{Definition}

CLAI is characterized by functional instability, the subjective complaint of recurring pain, swelling, instability, or giving way sensation of the lateral side of the ankle. The diagnosis was made when ankle instability persists for more than 6 months and confirmed by mechanical instability demonstrated by a pathological manual anterior drawer test (ADT) and talar tilt test [3], [21].

Broström repair is defined as anatomical repair and imbrication of the ATFL as well as the CFL, if required, with or without an anchor [6], [22]. Gould modified this technique by performing IER enhancement in addition to ATFL repair. IER enhancement was performed by suturing the proximal border of the IER to the fibula. This technique was known as Broström-Gould repair. Furthermore, this technique will be known as IER enhancement in this study [7], [23], [24]. Arthroscopic Broström repair is an ATFL repair combined with an arthroscopy procedure or an "all-inside" technique [19], [25]. in Table 1.

A variety of rehabilitation protocols is described

The AOFAS ankle-hindfoot scores [26] comprise pain, function, and alignment aspects. A maximum score of 100 points indicates a patient with no pain, full ROM (sagittal and hindfoot), no ankle or hindfoot instability, proper alignment, ability to walk more than six blocks, ability to ambulate on any walking surface, no observable limp, no restriction of daily or recreational activities, and no ambulation devices required.

The Karlsson-Peterson score [27], [28] assesses functional results by evaluating instability, pain, swelling, and stiffness related to activities of daily living, for instance, stair climbing, running, sporting activities, working capability, and leisure time activity. The highest score is 100 points. The visual analog scale [29] is a validated, subjective measure for acute and chronic pain. The score ranged between no pain (0) and worst pain (10).

Perioperative complications include nerve injury, knot pain, poor healing, skin complications (e.g., painful nodule, infection, and abscess), and musculoskeletal complications (e.g., ankle tightness) [30], [31], [32].

\section{Quality assessment}

The Newcastle-Ottawa scale was used to assess the quality of studies.

\section{Data extraction}

Three reviewers performed independent data extraction from the included studies. The reviewers 
Table 1: Baseline characteristics of the included studies

\begin{tabular}{|c|c|c|c|c|c|c|c|c|c|c|c|c|}
\hline Author & Study design & Inclusion criteria & Technique & Rehabilitation & $\begin{array}{l}\text { Number of } \\
\text { anchor } \\
\text { (s) }\end{array}$ & $\begin{array}{l}\text { Talar tilt } \\
(\mathrm{mm})\end{array}$ & $\begin{array}{l}\text { Anterior } \\
\text { drawer test } \\
(\mathrm{mm})\end{array}$ & Age & Male & BMI & $\begin{array}{l}\text { Mean } \\
\text { follow-up } \\
\text { (months) }\end{array}$ & NOS \\
\hline $\begin{array}{l}\text { Jeong et al. } \\
\text { (2014) }\end{array}$ & $\begin{array}{l}\text { Prospective } \\
\text { cohort }\end{array}$ & $\begin{array}{l}\text { CLAl, operated } \\
\text { between } \\
\text { February } 2011 \\
\text { and October } \\
2012\end{array}$ & $\begin{array}{l}\text { Arthroscopic } \\
\text { BP+IER } \\
\text { vs. } \\
\text { arthroscopic } \\
\text { BP }\end{array}$ & $\begin{array}{l}\text { - Non-weight-bearing was } \\
\text { maintained for } 6 \text { weeks after } \\
\text { surgery. } \\
\text { - Short leg cast immobilization } \\
\text { was maintained for } 4 \text { weeks after } \\
\text { surgery. } \\
\text { - Ankle ROM exercises were } \\
\text { allowed for } 2 \text { weeks with } \\
\text { protection of ankle orthosis. } \\
\text { - Six weeks after surgery } \\
\text { begins partial weight-bearing, } \\
\text { proprioception, and peroneal } \\
\text { muscle strengthening exercise. } \\
\text { - Light exercises began after } 3 \\
\text { months and gradually returned to } \\
\text { their normal sports activities }\end{array}$ & 1 vs. 1 & $\begin{array}{l}\text { Arthroscopic } \\
\text { BP+IER } \\
5.0 \pm 2 \text {. } \\
\text { Arthroscopic } \\
\text { BP } \\
4.9 \pm 0.9\end{array}$ & $\begin{array}{l}\text { (Talar anterior } \\
\text { translation) } \\
\text { Arthroscopic } \\
\text { BP+IER } \\
4.6 \pm 1.9 \\
\text { Arthroscopic } \\
\text { BP } \\
4.9 \pm 0.8\end{array}$ & 26.2 & 51.6 & $\mathrm{~N} / \mathrm{A}$ & $\begin{array}{l}19.5 \\
\text { vs. } \\
18.9\end{array}$ & 7 \\
\hline $\begin{array}{l}\text { Yeo et al. } \\
(2016)\end{array}$ & $\begin{array}{l}\text { Randomized } \\
\text { clinical trial }\end{array}$ & $\begin{array}{l}\text { CLAI, operated } \\
\text { between August } \\
2012 \text { and July } \\
2014\end{array}$ & $\begin{array}{l}\text { Arthroscopic } \\
\text { BP } \\
\text { vs. } \\
\text { Open BP+IER }\end{array}$ & $\begin{array}{l}\text { - All patients were placed in a } \\
\text { well-padded posterior splint with } \\
\text { the foot in slight dorsiflexion and } \\
\text { kept non-weight-bearing until } 2 \\
\text { weeks. } \\
\text { - Short leg walking cast for next } 2 \\
\text { weeks and protected progressive } \\
\text { weight-bearing was then allowed. } \\
\text { - During week 4-6, half-removed } \\
\text { cast or splint was applied and } \\
\text { started on gentle active assisted } \\
\text { ROM of the ankle and peroneal } \\
\text { strengthening exercise. } \\
\text { - Eight weeks postoperatively, } \\
\text { the patient began running and } \\
\text { functional activities. } \\
\text { - Cutting and sport-specific drills } \\
\text { were started by week } 12\end{array}$ & 1 vs. 1 & $\begin{array}{l}\text { Arthroscopic } \\
\text { BP } \\
3.9 \pm 1.5 \\
\text { Open } \\
\text { BP+lER } \\
3.8 \pm 3.6\end{array}$ & $\begin{array}{l}\text { Arthroscopic } \\
\text { BP } \\
6.7 \pm 1.3 \\
\text { Open } \\
\text { BP+IER } \\
6.8 \pm 2.1\end{array}$ & 34.8 & 39.6 & $\mathrm{~N} / \mathrm{A}$ & 12 vs. 12 & 9 \\
\hline $\begin{array}{l}\text { Araoye et al. } \\
(2017)\end{array}$ & $\begin{array}{l}\text { Retrospective } \\
\text { cohort }\end{array}$ & $\begin{array}{l}\text { CLAI, operated } \\
\text { between } 2006 \\
\text { and } 2016\end{array}$ & $\begin{array}{l}\text { Arthroscopic } \\
\text { BP+IER } \\
\text { vs. } \\
\text { Arthroscopic } \\
\text { BP }\end{array}$ & N/A & $\begin{array}{l}\text { Suture } \\
\text { anchor } \\
\text { vs. } \\
\text { Direct } \\
\text { suture }\end{array}$ & $N / A$ & N/A & 40 & 27.8 & 31.9 & 11.8 & 7 \\
\hline $\begin{array}{l}\text { Li et al. } \\
\text { (2017) }\end{array}$ & $\begin{array}{l}\text { Prospective } \\
\text { cohort }\end{array}$ & $\begin{array}{l}\text { CLAI, operated } \\
\text { between January } \\
2012 \text { and August } \\
2014\end{array}$ & $\begin{array}{l}\text { Arthroscopic } \\
\text { BP } \\
\text { vs. } \\
\text { Open } \\
\text { BP+IER }\end{array}$ & $\begin{array}{l}\text { - Isometric contraction from the } \\
\text { day after surgery. } \\
\text { - The ankle was immobilized in a } \\
\text { neutral position by short leg cast } \\
\text { - Two weeks after the surgery, the } \\
\text { cast was changed to an ankle } \\
\text { brace and passive ROM was } \\
\text { encouraged } \\
\text { - Weight-bearing was permitted } \\
\text { after } 4 \text { weeks }\end{array}$ & $\begin{array}{l}1 \text { or } 2 \\
\text { vs. } \\
1 \text { or } 2\end{array}$ & $N / A$ & N/A & 29.3 & 78.3 & 23.7 & $\begin{array}{l}39.7 \\
\text { vs. } \\
35.5\end{array}$ & 7 \\
\hline $\begin{array}{l}\text { Gang et al. } \\
(2020)\end{array}$ & $\begin{array}{l}\text { Retrospective } \\
\text { cohort }\end{array}$ & $\begin{array}{l}\text { CLAI, operated } \\
\text { between January } \\
2014 \text { and } \\
\text { January } 2017\end{array}$ & $\begin{array}{l}\text { Arthroscopic } \\
\text { BP } \\
\text { vs. } \\
\text { Open } \\
\text { BP+IER }\end{array}$ & $\begin{array}{l}\text { - Short leg cast was applied after } \\
\text { surgery and isometric contraction } \\
\text { was trained. } \\
\text { - After } 2 \text { weeks, short leg cast } \\
\text { was removed and replaced } \\
\text { by functional exercise brace, } \\
\text { and partial weight-bearing was } \\
\text { started. (active and passive ROM } \\
\text { exercise was initiated) } \\
\text { - Six weeks after surgery, the } \\
\text { patient began balance training, } \\
\text { endurance training, and transition } \\
\text { to full weight-bearing. }\end{array}$ & 1 vs. 1 & $\begin{array}{l}\text { Arthroscopic } \\
\text { BP } \\
3.3 \pm 0.8 \\
\text { Open } \\
\text { BP+IER } \\
3.1 \pm 0.4\end{array}$ & $\begin{array}{l}\text { (Anterior } \\
\text { displacement } \\
\text { of Talus) } \\
\text { Arthroscopic } \\
\text { BP } \\
3.2 \pm 0.4 \\
\text { Open } \\
\text { BP+IER } \\
3.3 \pm 0.5\end{array}$ & 38.4 & 70.1 & $N / A$ & 26 vs. 26 & 9 \\
\hline $\begin{array}{l}\text { Xu et al. } \\
(2020)\end{array}$ & $\begin{array}{l}\text { Retrospective } \\
\text { cohort }\end{array}$ & $\begin{array}{l}\text { CLAI } \\
\text { accompanied by } \\
\text { OLT, operated } \\
\text { between May } \\
2015 \text { and May } \\
2017\end{array}$ & $\begin{array}{l}\text { Arthroscopic } \\
\text { BP } \\
\text { vs. } \\
\text { Open } \\
\text { BP+IER }\end{array}$ & $\begin{array}{l}\text { - The ankle was protected by an } \\
\text { ankle brace for } 6 \text { weeks. } \\
\text { - Isometric contraction of muscle } \\
\text { groups was allowed from the day } \\
\text { after surgery } \\
\text { - Passive and active ROM was } \\
\text { allowed from the } 7^{\text {th }} \text { day after } \\
\text { surgery under ankle brace. } \\
\text { - Partial weight-bearing began } \\
\text { from the } 5^{\text {th }} \text { week after surgery } \\
\text { and full weight-bearing began } \\
\text { from } 7^{\text {th }} \text { week after surgery } \\
\text { - The patient could return to } \\
\text { high-impact physical activities for } \\
6 \text { months after surgery }\end{array}$ & $\begin{array}{l}1 \text { or } 2 \\
\text { vs. } \\
1 \text { or } 2\end{array}$ & N/A & $\mathrm{N} / \mathrm{A}$ & 34.8 & 73.1 & 23.7 & $\begin{array}{l}36.5 \\
\text { vs. } \\
39.1\end{array}$ & 9 \\
\hline
\end{tabular}


Table 1: (Continued)

\begin{tabular}{|c|c|c|c|c|c|c|c|c|c|c|c|c|}
\hline Author & Study design & Inclusion criteria & Technique & Rehabilitation & $\begin{array}{l}\text { Number of } \\
\text { anchor } \\
\text { (s) }\end{array}$ & $\begin{array}{l}\text { Talar tilt } \\
(\mathrm{mm})\end{array}$ & $\begin{array}{l}\text { Anterior } \\
\text { drawer test } \\
(\mathrm{mm})\end{array}$ & Age & Male & BMI & $\begin{array}{l}\text { Mean } \\
\text { follow-up } \\
\text { (months) }\end{array}$ & NOS \\
\hline $\begin{array}{l}\text { Zeng et al. } \\
(2020)\end{array}$ & $\begin{array}{l}\text { Retrospective } \\
\text { cohort }\end{array}$ & $\begin{array}{l}\text { CLAI, operated } \\
\text { between January } \\
2013 \text { and June } \\
2015\end{array}$ & $\begin{array}{l}\text { Arthroscopic } \\
\text { BP } \\
\text { vs. } \\
\text { open } \\
\text { BP+IER }\end{array}$ & $\begin{array}{l}\text { - The short leg cast was applied } \\
\text { until } 2 \text { weeks after surgery. } \\
\text { - After } 2 \text { weeks, short leg cast was } \\
\text { removed. Flexion and extension } \\
\text { of hip and knee were encouraged } \\
\text { - At } 3-6 \text { weeks after surgery, } \\
\text { patients began walking in a boot, } \\
\text { and strengthening exercises of } \\
\text { the whole lower extremity. } \\
\text { - The flexion and extension of } \\
\text { the ankle joint were passively } \\
\text { performed. } \\
\text { - At } 6-12 \text { weeks after surgery, } \\
\text { balance training and full } \\
\text { weight-bearing were performed }\end{array}$ & 1 vs. 1 & $\begin{array}{l}\text { Arthroscopic } \\
\text { BP } \\
2.7 \pm 1.2 \\
\text { Open } \\
\text { BP+IER } \\
2.4 \pm 1.3\end{array}$ & $\begin{array}{l}\text { Arthroscopic } \\
\text { BP } \\
3.3 \pm 1.3 \\
\text { Open } \\
\text { BP+IER } \\
2.8 \pm 1.1\end{array}$ & 29.7 & 81.5 & $\mathrm{~N} / \mathrm{A}$ & 36 vs. 36 & 9 \\
\hline
\end{tabular}

were not blinded to the authors and institution of the studies while undergoing review. Discrepancies were resolved by consensus among the three reviewers. Variables included authors, study design, age, sex, body mass index (BMI), operating technique, rehabilitation protocol, number of anchors, AOFAS, talar tilt, ADT, and follow-up.

\section{Statistical analysis}

Meta-analysis was performed using STATA 16. We performed a restricted maximum likelihood random effects meta-analysis to calculate the mean difference and $95 \%$ confidence interval of AOFAS, Karlsson score, talar tilt, and anterior drawer between the intervention and control groups. We performed a DerSimonian-Laird random effects meta-analysis to calculate the OR and $95 \%$ confidence interval for complications. I-squared $\left(\mathrm{I}^{2}\right)$ and Cochran $Q$ test were carried out to assess interstudy heterogeneity, in which $\mathrm{I}^{2}>50 \%$ and $\mathrm{p}<0.10$ indicate significant heterogeneity. Meta-regression analysis was performed for age, male, and BMI as covariates. We performed a sensitivity analysis by excluding a study with potential selection bias.

\section{Results}

\section{Baseline characteristics}

A total of 980 studies were obtained after duplication removal. After screening through the title and abstract according to the inclusion and exclusion criteria, 25 studies were assessed for eligibility. Ultimately, this systematic review and meta-analysis included 298 patients from seven studies (Figure 1). Baseline characteristics of the included studies are displayed in Table 1.

ATFL identified using arthroscopic examination was repaired with an "all-inside" arthroscopic technique without IER enhancement. Unidentified ATFL was repaired by an open technique with IER enhancement.

\section{Outcomes}

IER enhancement was associated with lower AOFAS (mean difference -1.115 [-2.197, -0.033], $\left.p=0.043 ; 1^{2:} 0 \%, p=1.000\right)$ (Figure 2a) during follow-up. Lower Karlsson score was observed in the IER enhancement group (mean difference $-2.004[-3.442,-0.567], p=0.006$; $\mathrm{I}^{2:} 3.71 \%, p=0.656$ ) (Figure $2 b$ ) during follow-up. Talar tilt (mean difference $-0.145^{\circ}[-0.436,0.146], p=0.329$; $\mathrm{I}^{2:} 0 \%, \mathrm{p}=0.808$ ) (Figure 3a) and anterior displacement (mean difference $-0.109 \mathrm{~mm}[-0.096,0.314], p=0.299$; $\left.1^{2:} 0 \%, p=0.769\right)$ in the two groups were similar on follow-up (Figure $3 \mathrm{~b}$ ). The complications were similar in both groups (OR $0.87[0.40,1.89], p=0.719 ; 1^{2:} 0 \%$, $p=0.693)$ (Figure 4).

\section{Arthroscopic with non-IER enhancement versus open IER enhancement}

AOFAS and Karlsson score between arthroscopic non-IER enhancement technique and open IER enhancement technique showed similar results with mean difference -1.11 [-2.20, -0.03], $\mathrm{p}=0.85 ; \mathrm{I} 2: 0 \%, \mathrm{p}=1.000$ and mean difference $-2.00[-3.44,-0.57], p=0.66 ; 12: 3.71 \%, p<0.001$, respectively.

\section{Sensitivity analysis}

Sensitivity analysis was performed to exclude Li et al. [33] study due to high risk of selection bias. In this analysis, IER enhancement was associated with lower AOFAS (mean difference -1.128 [-2.242, -0.014], $\left.p=0.047 ; 1^{2:} 0 \%, p=1.000\right)$ and Karlsson score (mean difference -2.052 [-3.563, -0.542], $p=0.008$; $\left.\mathrm{I}^{2:} 5.27 \%, p=0.518\right)$. Talar tilt (mean difference $-0.145^{\circ}$ $\left.[-0.436,0.146], p=0.329 ; I^{2:} 0 \%, p=0.808\right)$ and 


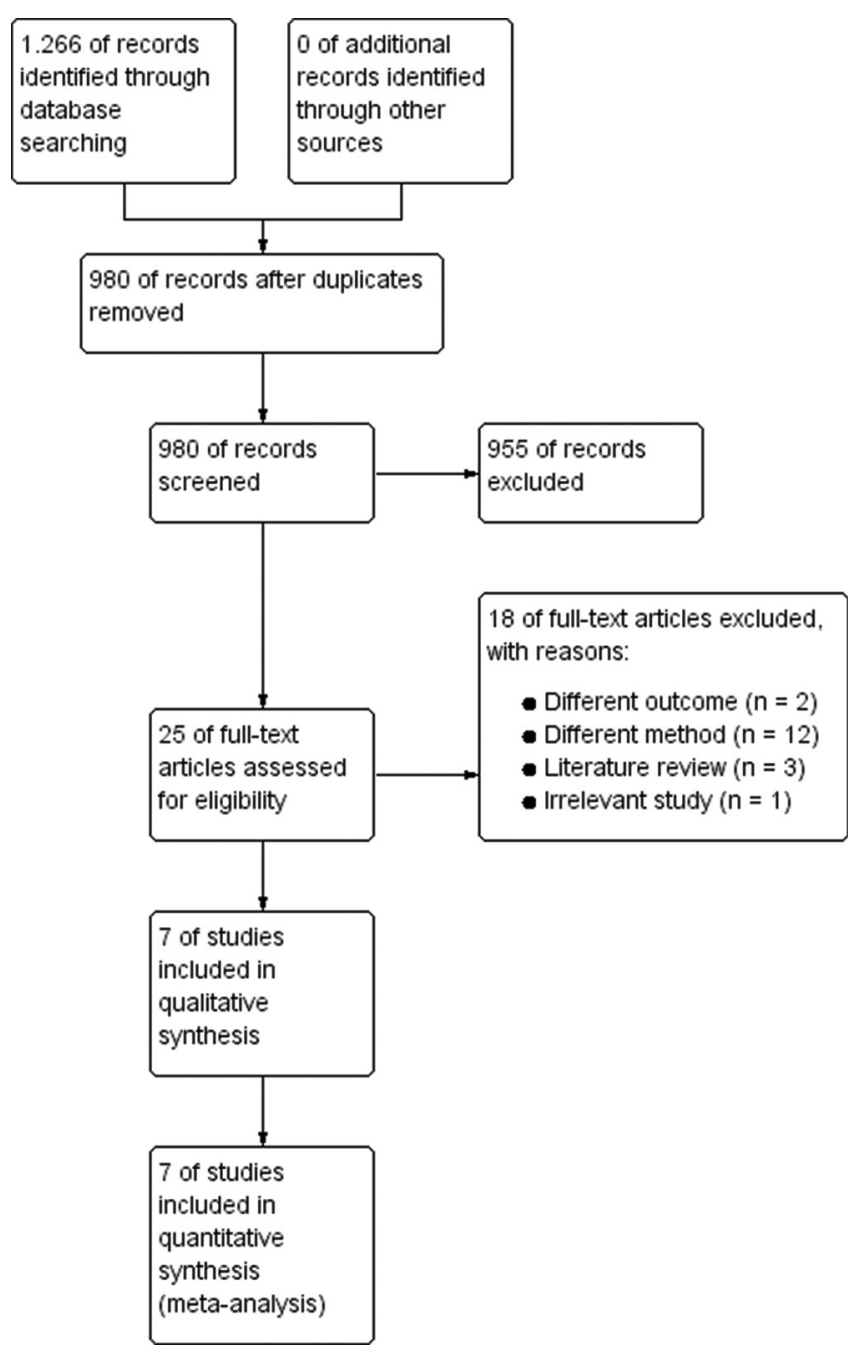

Figure 1: Preferred Reporting Items for Systematic Reviews and Meta-Analyses Flowchart

anterior displacement (mean difference $-0.109 \mathrm{~mm}$ $\left.[-0.096,0.314], p=0.299 ; I^{2:} 0 \%, p=0.769\right)$ in the two groups were similar. The complications were similar in both groups (OR $0.83[0.36,1.90], p=0.659 ; 1^{2:} 0 \%$, $p=0.545)$.

\section{Meta-regression}

Meta-regression analysis indicates that the association between IER and AOFAS was not affected by age $(p=0.927)$ and male gender $(p=0.930)$.

\section{Publication bias}

The funnel plot was symmetrical for AOFAS (Figure 5), talar tilt, and complications. Egger's test was not significant for AOFAS ( $p=0.938)$, Karlsson score $(p=0.140)$, talar tilt $(p=0.483)$, and complications $(p=0.391)$.

\section{Discussion}

The main clinical outcomes (AOFAS and Karlsson score) were worse in ATFL repair with IER enhancement, while talar tilt, anterior displacement, and complications were similar in both groups. The mean follow-up in the included studies ranged from 11.8 months to 39.7 months. The pooled effect estimates have a low heterogeneity; thus, the findings are similar despite differences in characteristics, arthroscopic or open surgery, and rehabilitation protocols. The low heterogeneity in pooled analysis indicates consistency. Regarding the difference between arthroscopic and open techniques, two studies compare arthroscopic nonIER enhancement and arthroscopic IER enhancement. Jeong et al. [24] showed no significant difference in terms of post-operative AOFAS score between the two groups. Araoye et al. [30] did not evaluate the AOFAS score in their study.

Four studies compared arthroscopic nonIER enhancement techniques and the open Broström procedure with the IER enhancement technique. There was no statistically significant difference in terms of AOFAS and Karlsson scores among the two groups.

A study by Li et al. [33] compared arthroscopic examination in the arthroscopic repair group with the open repair group, resulting in different patient selections between groups. Patients with unidentified ATFL remnants were operated on using the IER enhancement technique [34]. This may affect the outcome as there is a difference in ATFL quality between groups. To test the robustness of the pooled analysis, we performed a sensitivity analysis by removing $\mathrm{Li}$ et al. [33] study and the benefit in terms of AOFAS and Karlsson score remains statistically significant.

Even though there is no indication of smallstudy effects assessed by funnel plot and Egger's test, we cannot rule out publication bias due to assessment in $<10$ studies. Several studies showed that age might affect ligament healing [35], [36]. However, meta-regression analysis indicates that the change in the AOFAS score does not vary by age or gender. It may be caused by the patient's age in these studies distributed normally. Several confounding variables have been excluded or controlled in its studies, such as an osteochondral lesion, ankle fracture, and subtalar joint sprain. Unfortunately, we cannot provide comprehensive meta-regression analysis due to limited studies, and confounders are not reported adequately by the studies. The other confounders included CFL repair, periosteal flap, anchors, and hyperlaxity. Rehabilitation protocols vary among the included studies and may potentially confound. Nevertheless, despite the inadequate address of these confounders, $0 \%$ heterogeneity in most outcomes indicates that the findings are generalizable. 


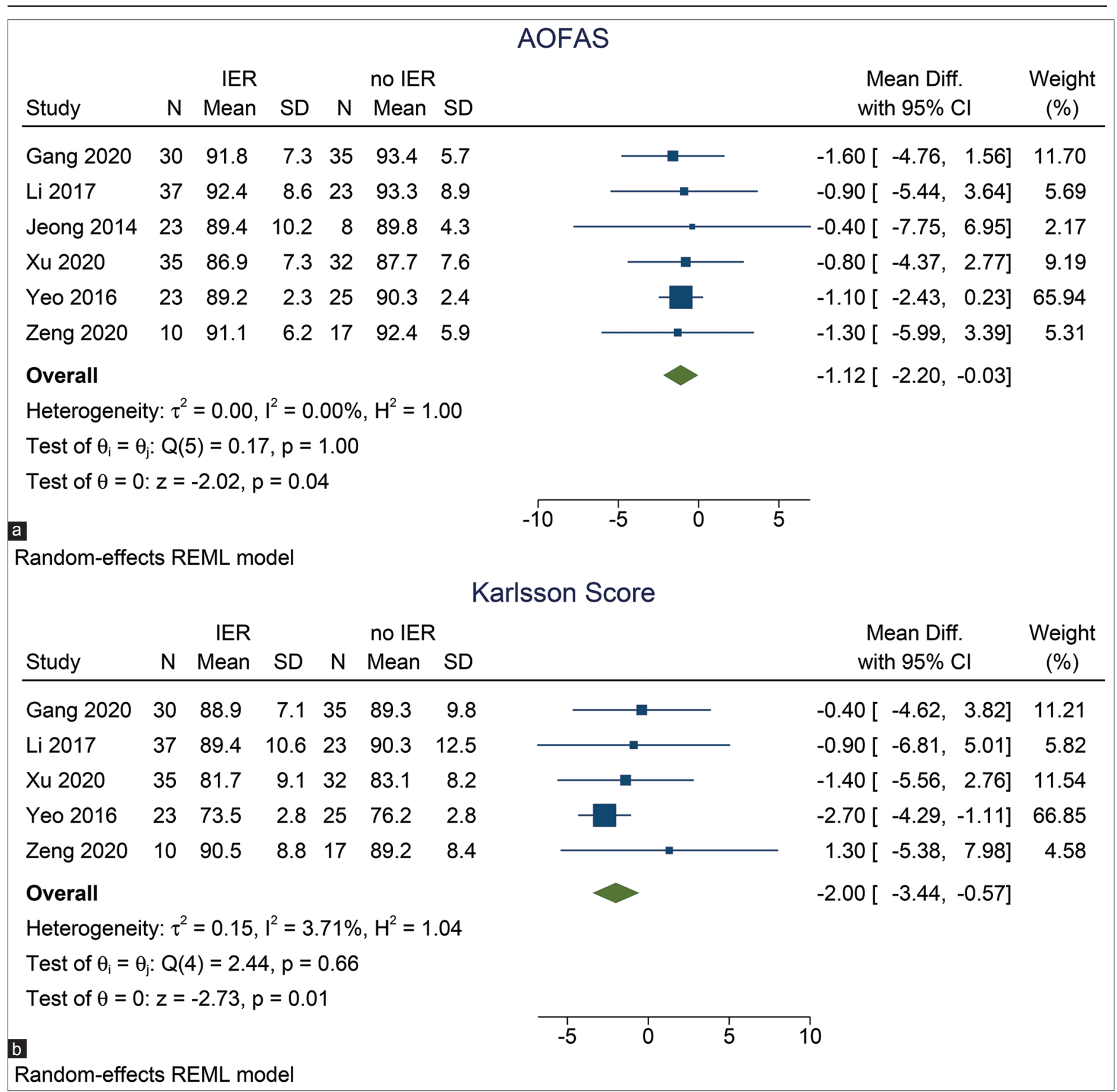

Figure 2: Functional outcome. AOFAS (a) and Karlsson (b). AOFAS: American Orthopaedic Foot and Ankle Society

Meta-analysis shows that ATFL repair with non-IER enhancement was better than IER enhancement in AOFAS and Karlsson score. These findings are supported by several studies, including those exploring biomechanical comparisons in cadaveric studies. There are no significant differences in anterior displacement and talar tilt outcome between ATFL repair with and without IER enhancement [15], [16], [17]. Although a cadaveric study shows some IER enhancement benefits [14], it may not translate into clinical outcomes.

The minimal clinically important difference (MCID) of AOFAS and Karlsson score in CLAI has not yet been established. The included studies did not report the proportion of patients achieving MCID in both groups, so we cannot compare the ratio for achieving
MCID. The advantage of functional score remains to be investigated. However, due to only slight differences, it is not likely that the advantage of non-IER enhancement in this pooled analysis will be clinically relevant. Thus, non-IER enhancement is non-inferior compared to IER enhancement.

Performing IER enhancement is not always feasible in these conditions: (1) Missing IER; (2) X-shaped IER; and (3) far distance to the fibular tip [24]. Furthermore, the correlation between IER and superficial peroneal nerve should be considered [37], [38].

\section{Clinical implication}

Meta-analysis showed that ATFL repair with non-IER enhancement was not inferior compared 


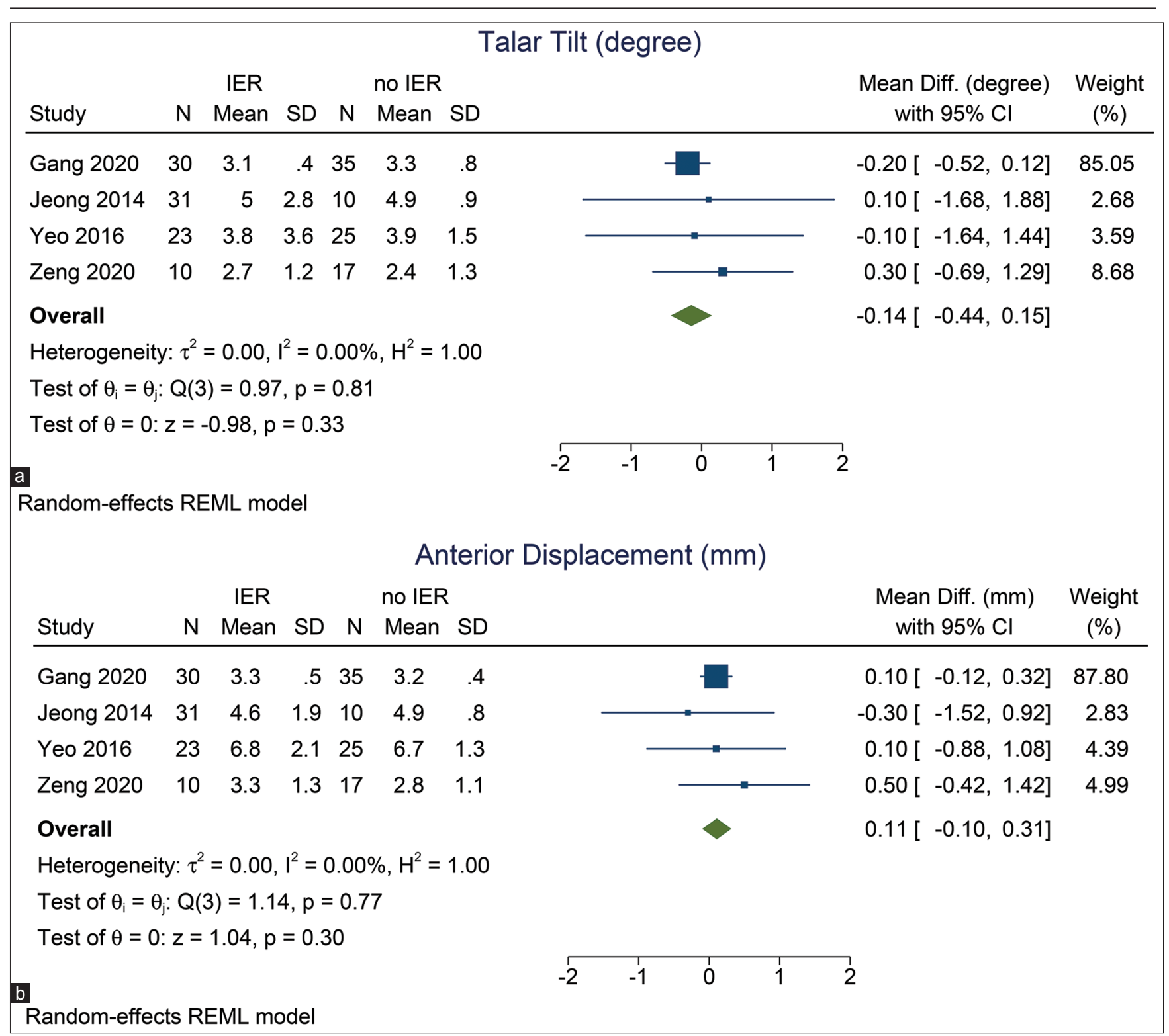

Figure 3: Radiologic outcome. Talar tilt (a) and anterior displacement (b)

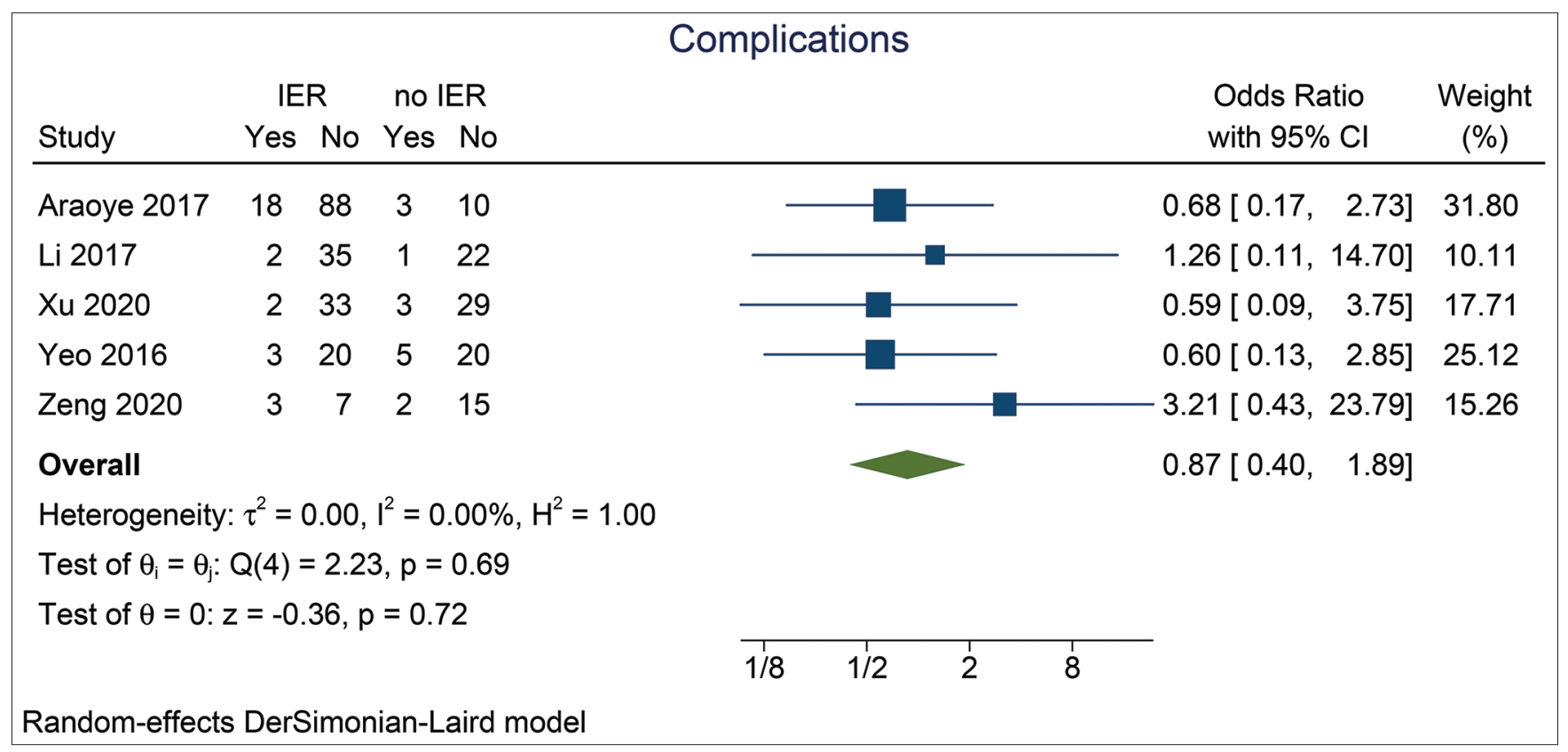

Figure 4: Complications 


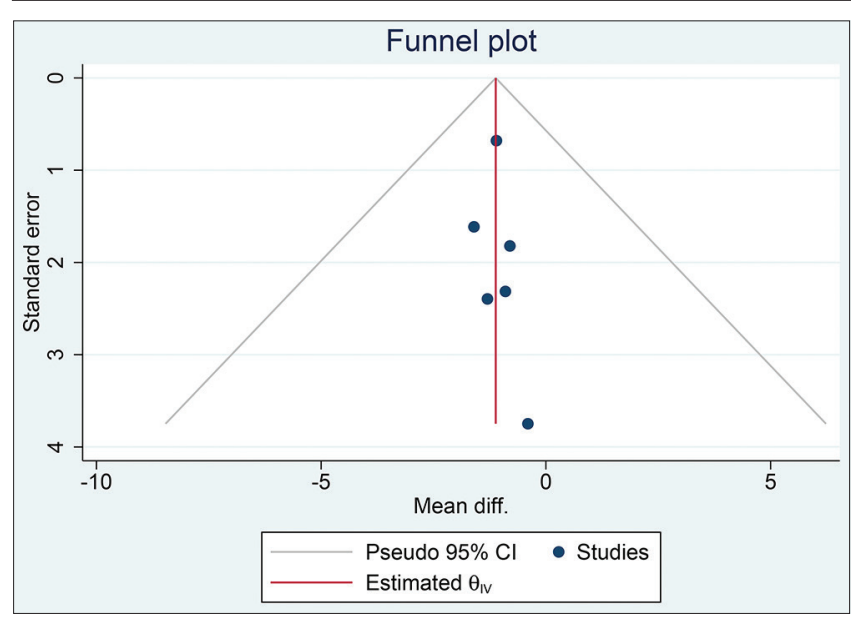

Figure 5: Funnel plot analysis for AOFAS. AOFAS: American Orthopaedic Foot and Ankle Society

to those with IER enhancement. The authors of this study recommend non-IER enhancement as the primary surgical approach for managing CLAI. IER enhancement can be performed whenever ATFL is unidentified or when the quality of the ATFL remnant is low.

\section{Limitations}

The limitation of this study includes low certainty of the evidence of studies. It is because most of the studies are observational and retrospective, thus were prone to biases. Only one RCT generates a higher certainty of the evidence. Many of the studies did not report potential confounders, which may affect the result. Further study with a randomized clinical trial design is recommended with appropriate control of confounders, such as CFL injury/repair, periosteal flap, anchor utilization, and hyperlaxity patient.

\section{Conclusion}

This meta-analysis showed that ATFL repair with non-IER enhancement was non-inferior compared to those with IER enhancement.

\section{Declaration}

\section{Consent for publication}

All authors approved the final version of the manuscript.

\section{Availability of data and materials}

Data are available at the reasonable request.

\section{Authors' contributions}

John Butarbutar: Conceptualization, data curation, formal analysis, investigation, validation, writing - original draft, and writing - review and editing. Irvan: Data curation, formal analysis, investigation, validation, and writing - original draft. Michael Anthonius Lim: Data Curation, Formal analysis, investigation, validation, and writing - original draft. Raymond Pranata: Data Curation, formal analysis, investigation, validation, writing - original draft, and writing - review and editing.

\section{CRD42021227223}

PROSPERO registration number:

\section{References}

1. Mugno AT, Constant D. Recurrent Ankle Sprain. Treasure Island, FL: StatPearls Publishing; 2020

2. Gribble PA, Bleakley CM, Caulfield BM, Docherty CL, Fourchet F, Fong DT, et al. Evidence review for the 2016 international ankle consortium consensus statement on the prevalence, impact and long-term consequences of lateral ankle sprains. $\mathrm{Br} J$ Sports Med. 2016;50(24):1496-505. https://doi.org/10.1136/ bjsports-2016-096189

PMid:27259753

3. Peters JW, Trevino SG, Renstrom PA. Chronic lateral ankle instability. Foot Ankle. 1991;12(3):182-91. https://doi. org/10.1177/107110079101200310

PMid:1791012

4. Lopes R, Andrieu M, Cordier G, Molinier F, Benoist J, Colin F, et al. Arthroscopic treatment of chronic ankle instability: Prospective study of outcomes in 286 patients. Orthop Traumatol Surg Res. 2018;104(8S):S199-205. https://doi.org/10.1016/j. otsr.2018.09.005

PMid:30245066

5. Yasui Y, Murawski CD, Wollstein A, Takao M, Kennedy JG Operative treatment of lateral ankle instability. JBJS Rev. 2016;4(5):e6. https://doi.org/10.2106/JBJS.RVW.15.00074 PMid:27490220

6. Broström L. Sprained ankles. VI. Surgical treatment of "chronic" ligament ruptures. Acta Chir Scand. 1966;132(5):551-65. PMid:5339635

7. Gould N, Seligson D, Gassman J. Early and late repair of lateral ligament of the ankle. Foot Ankle. 1980;1(2):84-9. https://doi. org/10.1177/107110078000100206

PMid:7274903

8. Knupp M, Lang TH, Zwicky L, Lötscher P, Hintermann B Chronic ankle instability (medial and lateral). Clin Sports Med. 2015;34(4):679-88. https://doi.org/10.1016/j.csm.2015.06.004 PMid:26409589

9. Petrera M, Dwyer T, Theodoropoulos JS, Ogilvie-Harris DJ. Short-to medium-term outcomes after a modified broström repair for lateral ankle instability with immediate postoperative weightbearing. Am J Sports Med. 2014;42(7):1542-8. https:// 
doi.org/10.1177/0363546514530668

PMid:24769409

10. Li X, Killie H, Guerrero P, Busconi BD. Anatomical reconstruction for chronic lateral ankle instability in the high-demand athlete: Functional outcomes after the modified broström repair using suture anchors. Am J Sports Med. 2009;37(3):488-94. https:// doi.org/10.1177/0363546508327541

PMid:19251684

11. Baumhauer JF, O'Brien T. Surgical considerations in the treatment of ankle instability. J Athl Train. 2002;37(4):458-62.

PMid: 12937567

12. Shahrulazua A, Sukimin MS, Muzaffar TM, Yusof MI. Early functional outcome of a modified brostrom-gould surgery using bioabsorbable suture anchor for chronic lateral ankle instability. Singapore Med J. 2010;51(3):235-41.

PMid:20428746

13. Bajuri MY, Daun E, Abdul Raof MH, Hassan MR, Das S. Functional outcome of modified brostrom-gould procedure using the poplok knotless suture anchor technique in lateral ankle instability. Cureus. 2019;11(6):e4971. https://doi.org/10.7759/ cureus.4971

PMid:31497416

14. Aydogan U, Glisson RR, Nunley JA. Extensor retinaculum augmentation reinforces anterior talofibular ligament repair. Clin Orthop Relat Res. 2006;442:210-5. https://doi.org/10.1097/01. blo.0000183737.43245.26

PMid: 16394763

15. Behrens SB, Drakos M, Lee BJ, Paller D, Hoffman E, Koruprolu S, et al. Biomechanical analysis of brostrom versus brostrom-gould lateral ankle instability repairs. Foot Ankle Int 2013;34(4):587-92. https://doi.org/10.1177/1071100713477622 PMid:23391625

16. Brown CA, Hurwit D, BehnA, Hunt KJ. Biomechanical comparison of an all-soft suture anchor with a modified broström-gould suture repair for lateral ligament reconstruction. Am J Sports Med. 2014;42(2):417-22. https://doi.org/10.1177/0363546513517873 PMid:24401683

17. Rigby RB, Cottom JM. A comparison of the "all-inside" arthroscopic broström procedure with the traditional open modified broström-gould technique: A review of 62 patients. Foot Ankle Surg. 2019;25(1):31-6. https://doi.org/10.1016/j. fas.2017.07.642 PMid:29409264

18. Bell SJ, Mologne TS, Sitler DF, Cox JS. Twenty-six-year results after broström procedure for chronic lateral ankle instability. Am J Sports Med. 2006;34(6):975-8. https://doi. org/10.1177/0363546505282616

PMid:16399935

19. Guillo S, Odagiri H. All-inside endoscopic broström-gould technique. Arthrosc Tech. 2020;9(1):e79-84. https://doi. org/10.1016/j.eats.2019.09.003

PMid:32021778

20. Cottom JM, Rigby RB. The "all inside" arthroscopic broström procedure: A prospective study of 40 consecutive patients. J Foot Ankle Surg. 2013;52(5):568-74. https://doi.org/10.1053/j. jfas.2013.02.022 PMid:23669003

21. Hertel J. Functional anatomy, pathomechanics, and pathophysiology of lateral ankle instability. J Athl Train. 2002;37(4):364-75.

PMid:12937557

22. Hunt KJ, Griffith R. Open brostrom for lateral ligament stabilization. Curr Rev Musculoskelet Med. 2020;13(6):788-96. https://doi.org/10.1007/s12178-020-09679-z

\section{PMid:33159666}

23. Lee KT, Park YU, Kim JS, Kim JB, Kim KC, Kang SK. Long-term results after modified brostrom procedure without calcaneofibular ligament reconstruction. Foot Ankle Int. 2011;32(2):153-7. https://doi.org/10.3113/FAI.2011.0153 PMid:21288414

24. JeongBO, Kim MS, Song WJ, SooHoo NF. Feasibility and outcome of inferior extensor retinaculum reinforcement in modified broström procedures. Foot Ankle Int. 2014;35(11):1137-42. https://doi.org/10.1177/1071100714543645 PMid:25037711

25. Matsui K, Takao M, Miyamoto W, Innami K, Matsushita T. Arthroscopic broström repair with gould augmentation via an accessory anterolateral port for lateral instability of the ankle. Arch Orthop Trauma Surg. 2014;134(10):1461-7. https://doi. org/10.1007/s00402-014-2049-x PMid:25015792

26. Kitaoka HB, Alexander IJ, Adelaar RS, Nunley JA, Myerson MS Sanders M. Clinical rating systems for the ankle-hindfoot, midfoot, hallux, and lesser toes. Foot Ankle Int. 1994;15(7):349-53. https://doi.org/10.1177/107110079401500701

\section{PMid:7951968}

27. Karlsson J, Peterson L. Evaluation of ankle joint function: The use of a scoring scale. Foot. 1991;1:15-9.

28. Karlsson J, Eriksson BI, Bergsten T, Rudholm O, Swärd L. Comparison of two anatomic reconstructions for chronic lateral instability of the ankle joint. Am J Sports Med. 1997;25(1):48-53. https://doi.org/10.1177/036354659702500109 PMid:9006691

29. Delgado DA, Lambert BS, Boutris N, McCulloch PC, Robbins AB Moreno MR, et al. Validation of digital visual analog scale pain scoring with a traditional paper-based visual analog scale in adults. J Am Acad Orthop Surg Glob Res Rev. 2018;2(3):e088. https://doi.org/10.5435/JAAOSGlobal-D-17-00088 PMid:30211382

30. Araoye I, de Cesar Netto C, Cone B, Hudson P, Sahranavard B Shah A. Results of lateral ankle ligament repair surgery in one hundred and nineteen patients: Do surgical method and arthroscopy timing matter? Int Orthop. 2017;41(11):2289-95. https://doi.org/10.1007/s00264-017-3617-9

PMid:28842780

31. Yeo ED, Lee KT, Sung IH, Lee SG, Lee YK. Comparison of all-inside arthroscopic and open techniques for the modified broström procedure for ankle instability. Foot Ankle Int. 2016;37(10):1037-45. https://doi. org/10.1177/1071100716666508 PMid:27623732

32. Zeng G, Hu X, Liu W, Qiu X, Yang T, Li C, et al. Open broström-gould repair vs arthroscopic anatomical repair of the anterior talofibular ligament for chronic lateral ankle instability. Foot Ankle Int. 2020;41(1):44-9. https://doi. org/10.1177/1071100719875964 PMid:31535563

33. Li H, Hua Y, Li H, Ma K, Li S, Chen S. Activity level and function 2 years after anterior talofibular ligament repair: A comparison between arthroscopic repair and open repair procedures. Am J Sports Med. 2017;45(9):2044-51. https://doi. org/10.1177/0363546517698675

\section{PMid:28394631}

34. Caputo AM, Lee JY, Spritzer CE, Easley ME, DeOrio JK Nunley JA $2^{\text {nd }}$, et al. In vivo kinematics of the tibiotalar joint after lateral ankle instability. Am J Sports Med. 2009;37(11):2241-8. https://doi.org/10.1177/0363546509337578

PMid:19622791

35. Ihara $\mathrm{H}$, Kawano $\mathrm{T}$. Influence of age on healing capacity 
of acute tears of the anterior cruciate ligament based on magnetic resonance imaging assessment. $\mathrm{J}$ Comput Assist Tomogr. 2017;41(2):206-11. https://doi.org/10.1097/ RCT.0000000000000515

\section{PMid:28045756}

36. Nakano N, Matsumoto T, Takayama K, Matsushita T, Araki D, Uefuji A, et al. Age-dependent healing potential of anterior cruciate ligament remnant-derived cells. Am J Sports Med. 2015;43(3):700-8. https://doi.org/10.1177/0363546514561436 PMid:25556219
37. Dalmau-Pastor M, Malagelada F, Kerkhoffs GM Manzanares MC, Vega J. X-shaped inferior extensor retinaculum and its doubtful use in the bröstrom-gould procedure. Knee Surg Sports Traumatol Arthrosc. 2018;26(7):2171-6. https://doi. org/10.1007/s00167-017-4647-y

PMid:28710509

38. Jorge JT, Gomes TM, Oliva XM. An anatomical study about the arthroscopic repair of the lateral ligament of the ankle. Foot Ankle Surg. 2018;24(2):143-8. https://doi.org/10.1016/j.fas.2017.01.005 PMid:29409223 